\title{
Segregación espacial, empleo y pobreza en Montevideo
}

\author{
Rubén Kaztman y Alejandro R etamoso
}

$\mathrm{E}$

ste artículo examina dos procesos que están afectando las características de la pobreza en la ciudad de Montevideo: el debilitamiento de los vínculos de los trabajadores menos calificados con el mercado de trabajo y la creciente concentración de esos trabajadores en barrios con alta densidad de pobreza. Los resultados, si bien están lejos de ser concluyentes, sugieren la conveniencia de investigar más a fondo la relación entre las transformaciones en la morfología social de las ciudades y la segmentación de sus mercados de trabajo. De corroborarse las tendencias a una polarización creciente en la distribución espacial de las clases en las ciudades, y de verificarse que en los barrios más desaventajados se activan mecanismos que realimentan el aislamiento social de sus residentes, estaríamos en presencia de procesos que, a

Rubén Kaztman

Director del Programa de Investigación sobre Integración,

Pobreza y Exclusión Social (IPES)

Universidad Católica de Uruguay

œ kaztman@adinet.com.uy

Alejandro Retamoso

Investigador Asociado del IPES,

Universidad Católica de Uruguay

- aretamo@ine.gub.uy menos de ser contrarrestados de manera efectiva, ampliarán irremediablemente las desigualdades, ya excesivamente altas, que sufren las grandes ciudades latinoamericanas. 


\section{Introducción: empleo, concentración espacial} y endurecimiento de la pobreza urbana

Entre las ciudades de América Latina, Montevideo se ha distinguido por sus niveles relativamente bajos de desigualdad y pobreza. Durante el período de gobierno militar ese perfil sufrió deterioros importantes, pero a partir de 1985, con la reapertura democrática y por espacio de una década, la estructura social de la ciudad fue recobrando los rasgos que la marcaron en el pasado. En particular, se observó un descenso continuo del porcentaje de hogares por debajo de la línea de pobreza (gráfico 1).

Sin embargo, a mediados del decenio de 1990 esa tendencia se revirtió. Desde entonces y hasta 2001 los índices de pobreza exhibieron aumentos leves y, con posterioridad, un alza brusca producto de la crisis financiera del 2002. Como resultado, en 2003 la pobreza afectaba aproximadamente a un quinto de los hogares de la capital uruguaya.

El actual aumento de la pobreza está asociado a un cambio significativo en sus características. Se trata de un marcado debilitamiento de los vínculos que las personas de poca calificación pueden establecer con el mercado de trabajo - y que se expresa en niveles altos de desempleo, precariedad e inestabilidad laboral, en niveles bajos de remuneraciones- $-\mathrm{y}$ en un aumento en todas estas dimensiones de la brecha con los trabajadores más calificados (Kaztman, 2002; Amarante, Arim y Vigorito, 2004). Como estas tendencias están ancladas en aspectos centrales de las nuevas modalidades de acumulación, anuncian un endurecimiento progresivo de la pobreza y, por ende, dificultades crecientes para que los hogares superen esa situación.

Numerosos estudios realizados en Uruguay muestran que la mayor parte de las variaciones en los índices de pobreza y en sus características obedece a cambios en el mercado de trabajo. ${ }^{1}$ Sin dejar de reconocer

\footnotetext{
${ }^{1}$ El resultado del plebiscito de 1989 sobre la indexación de jubilaciones y pensiones también tuvo un impacto importante sobre la evolución de la pobreza. El plebiscito implicó la aprobación de una enmienda a la constitución por la cual los pagos a los sectores pasivos pasaron a reajustarse, de acuerdo al índice de aumento de los salarios del trimestre anterior y cuya aplicación produjo importantes aumentos de las jubilaciones y pensiones.
}

la potencia de esa línea explicativa, los resultados de una serie de investigaciones recientes revelan la conveniencia de ampliar el marco interpretativo para que incorpore las profundas transformaciones que afectan el tejido social de la ciudad. Esas transformaciones, menos visibles que las que ocurren en el mercado de trabajo, deterioran la salud de los mecanismos que a lo largo del siglo pasado habrían permitido a muchos hogares superar la pobreza. Nos referimos a segmentaciones crecientes en la calidad de los servicios (salud, educación, vivienda) a los que acceden las distintas clases sociales, junto con un aumento de la concentración de los hogares pobres en el territorio urbano.

Este último fenómeno está atrayendo la atención de las ciencias sociales de la región. Retomando una tradición que inicia un artículo seminal de Park (1926), se observa un interés creciente por la exploración sistemática de los efectos de la concentración espacial de la pobreza urbana sobre su endurecimiento y perpetuación. ${ }^{2}$ Desde esa perspectiva, que bajo el rótulo de "segregación residencial" agrupa hoy día numerosos trabajos académicos, se otorga gran importancia a los efectos del entorno social de los lugares de residencia sobre las posibilidades que tienen las personas y los hogares pobres de mejorar sus condiciones de vida. Los vecindarios son vistos como contextos ecológicos que mediatizan el acceso de las personas a las fuentes más importantes de activos físicos, sociales o humanos localizadas en el mercado, en el Estado y en la comunidad. Esa mediación se produce principalmente por dos vías. De un lado, por el estrechamiento progresivo de los ámbitos de interacción con otras clases sociales y, de otro, por un aumento de las diferencias entre los

\footnotetext{
${ }^{2}$ Más allá de sus excelentes aportes a la medición de la segregación residencial en los países latinoamericanos, un trabajo reciente de Rodríguez y C. Arriagada (2004) pasa revista detallada a los estudios sobre el tema en América Latina señalando, además, las líneas más promisorias de investigación para futuros avances en este campo. En Jencks y Mayer (1990) y en Sampson, Morenoff y Gannon-Rowley (2002) se hace una exhaustiva revisión de la literatura estadounidense acerca de los efectos del vecindario sobre distintos tipos de comportamiento.
} 
Montevideo: Evolución de la tasa de desempleo y del porcentaje de hogares por debajo de la línea de pobreza, 1986-2003

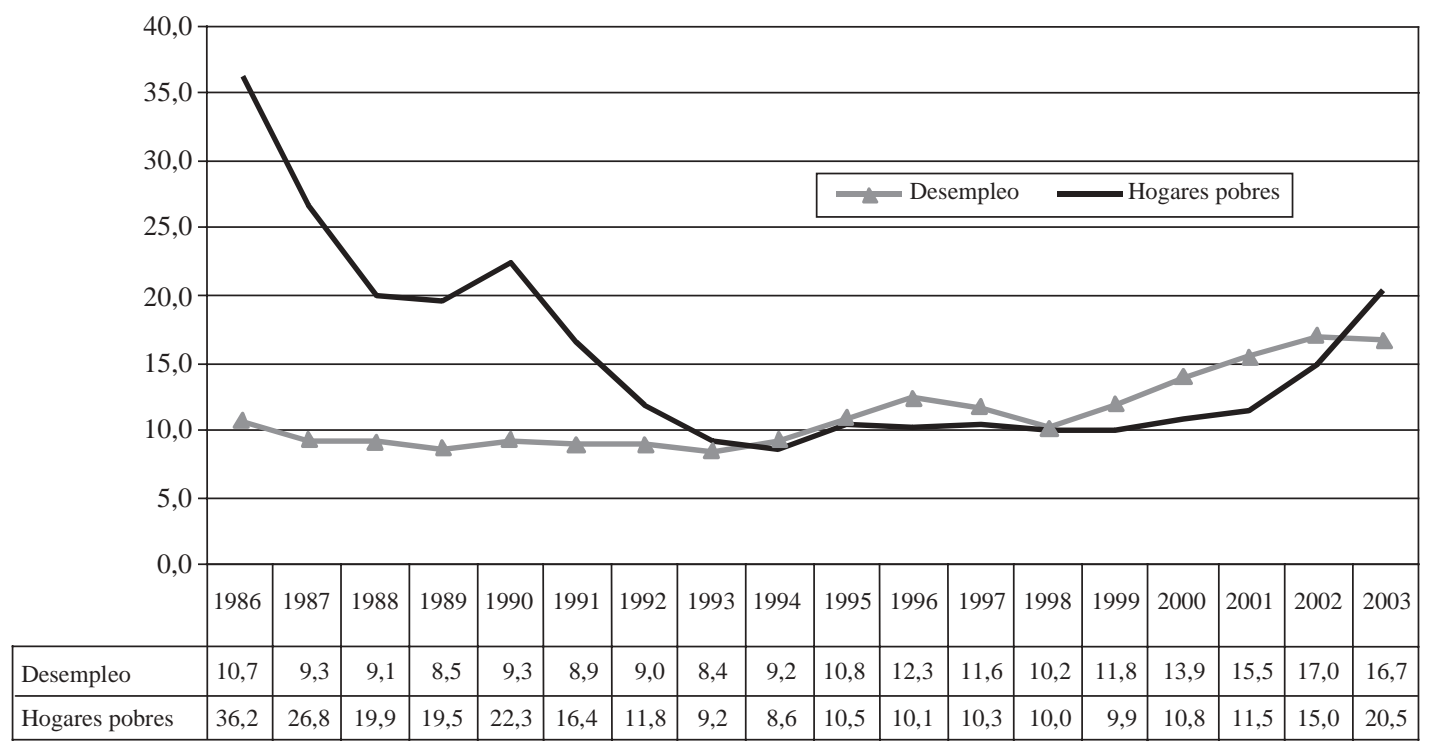

Fuente: Elaboración propia con datos del Instituto Nacional de Estadística (INE), de Uruguay.

barrios pobres y el resto de los barrios de la ciudad, en cuanto a la calidad de los servicios y de las instituciones. Según este enfoque, la residencia en barrios con altas concentraciones de pobreza agregaría desventajas importantes a aquellas que, en estructuras productivas organizadas cada vez más en torno al conocimiento, se derivan de las bajas calificaciones relativas de los residentes.

Si bien todavía es temprano para hacer afirmaciones concluyentes, los resultados de los trabajos emprendidos bajo este enfoque bastan para aceptar que la consideración conjunta de las transformaciones en el mercado laboral y en la segregación espacial de las clases enriquece nuestra capacidad para comprender tanto los cambios que se están produciendo en la naturaleza de la pobreza urbana, como algunos aspectos centrales de la inequidad de las estructuras sociales urbanas.

Este artículo examinará en las seccciones que siguen la evidencia existente sobre tendencias a la concentración espacial de los pobres en Montevideo. Co- mentará brevemente los resultados de los estudios sobre la evolución del empleo y, en particular, sobre los cambios en la situación de los menos calificados en el mercado de trabajo. Analizará la relación entre ambos fenómenos, haciendo hincapié en el lado menos conocido y estudiado de esa relación, esto es, en los efectos de los vecindarios sobre el vínculo de los residentes con el mercado laboral. Por último, extraerá algunas conclusiones sobre el papel que pueden estar desempeñando los procesos de segregación en las posibilidades de alcanzar mayores niveles de equidad en la estructura social de la ciudad.

Como el interés de este trabajo es examinar y discutir procesos estructurales de largo plazo, hemos procurado sortear los períodos claramente afectados por crisis coyunturales como las que sufrió Uruguay en los últimos años del siglo pasado y, particularmente, la que se desencadenó a inicios del 2002. Por tal motivo, el entramado de evidencias que se utilizará para poner a prueba la consistencia del marco conceptual adoptado se limitará a la última década del siglo XX. 


\section{II}

\section{Los procesos de segregación espacial en Montevideo}

A través de índices diversos, los cuadros siguientes muestran los cambios que ha experimentado la distribución espacial de las clases en Montevideo entre las décadas de 1980 y de 1990. En efecto, del cuadro 1 se desprende un incremento significativo de la homogeneidad en la composición social de los barrios, que se refleja en los índices de segregación residencial y de disimilitud de Duncan para hogares clasificados por distintas variables de estatus social y condiciones de vida. ${ }^{3} \mathrm{El}$ incremento de la concentración geográfica de población con condiciones de vida similares se observa en los indicadores de ingreso de los hogares, de nivel educativo, de empleo y de tipo de inserción laboral de los jefes de hogar. Estos resultados son congruentes con otras mediciones (Kaztman, 1999; Pellegrino, Macadar y otros, 2002).

Pese a la significativa reducción de la pobreza que registraron todos los barrios de Montevideo en las décadas de 1980 y de 1990, en ese período el proceso de convergencia de las familias con escasos ingresos en los barrios más pobres se acentuó considerablemente. De esta forma, como se observa en el cuadro 2 , en las tres zonas (o grupos de barrios) de la ciudad con mayores carencias la concentración subió del $65 \%$ de las personas pobres al $78 \%$ de las personas pobres, y del $78 \%$ al $84 \%$ de los indigentes del departamento. Paralelamente, estos mismos barrios, ubicados en la periferia de la ciudad, también acrecentaron su contribución a la población total.

Por su parte, el cuadro 3 permite concluir que los barrios que exhibieron un crecimiento demográfico

\footnotetext{
${ }^{3}$ El índice de disimilitud de Duncan es un indicador sintético de la relación que existe entre la composición de las subunidades territoriales (social, laboral, racial, etc.) y la composición social de la unidad territorial superior (ciudad o aglomerado urbano). Si la composición de una y otra difieren, estaremos en presencia de segregación residencial, pues la distribución de los grupos sociales entre las subunidades territoriales estaría desalineada respecto a la representación del grupo en toda la ciudad o aglomeración superior. El recorrido de la medida es de 0 (segregación nula) a 100 (segregación total en donde ninguna subunidad registra composición mixta). En cambio, el índice de segregación residencial que se utiliza en este trabajo indica la proporción de la varianza total que se explica por la varianza entre subunidades territoriales.
}

mayor son aquellos de menor densidad inicial y cuya transformación resultó de desplazamientos que se produjeron principalmente desde las zonas centrales a las periféricas de la ciudad. A este respecto, se debe subrayar el notable aumento de los asentamientos irregulares los que, si bien fueron tomando cuerpo con las crisis económicas de los decenios de 1970 y 1980, recibieron un fuerte impulso a partir de la apertura democrática, en 1985.

El panorama se completa con los datos del cuadro 4, los que muestran que los barrios receptores de población son precisamente los que presentan las características sociales más desventajosas, esto es, una alta densidad de hogares con carencias y una elevada incidencia de factores de riesgo. Paralelamente, también se produjeron desplazamientos de las clases medias y altas hacia los barrios del este de la ciudad. Con la consiguiente ampliación de la distancia física entre las clases, comenzó a tomar forma en Montevideo un nivel de segregación espacial bien conocido en otras grandes ciudades latinoamericanas.

\section{1. ¿Qué hay de nuevo en la actual segregación residencial urbana?}

Pese a las tendencias anteriores, se podría aducir que en la historia de Montevideo del siglo XX siempre hubo diferencias claras en la localización de las clases en el suelo urbano. Caben al menos tres posibles cuestionamientos frente a esa afirmación, los que hacen a las dimensiones cuantitativas y cualitativas del fenómeno.

El primer cuestionamiento subraya diferencias en la intensidad del fenómeno y descansa en la importancia que tiene su acentuación para la homogeneidad en la composición social de los barrios. Esto es, sin desconocer la existencia previa de segregación espacial en la ciudad, lo que se dice es que ahora los niveles de esa segregación son mucho mayores.

El segundo cuestionamiento se basa en que los residentes de los barrios homogéneamente pobres de la ciudad están ahora menos integrados al resto de la 
CUADRO 1

Montevideo: Evolución del índice de segregación residencial (ISR) y del índice de disimilitud en los barrios

\begin{tabular}{lccc}
\hline Variable & Indicador & 1986-1987-1988 & $\begin{array}{c}\text { Variación relativa } \\
(\%)\end{array}$ \\
\hline Ingreso per cápita del hogar & ISR & $1997-1998,36$ & 21,94 \\
Ingreso por trabajo del hogar, per cápita & ISR & 14,49 & 18,43 \\
Promedio educativo de mayores 26 años por hogar & ISR & 21,69 & 26,02 \\
Hogares cuyo jefe tiene ocupación de alto estatus & Disimilitud & $32 \%$ & $35 \%$ \\
Desempleo & Disimilitud & $9 \%$ & $13 \%$ \\
Cuenta propia sin local (no profesionales) & Disimilitud & $13 \%$ & 10 \\
\hline
\end{tabular}

Fuente: Cervini y Gallo (2001), a partir de la Encuesta Continua de Hogares (ECH) del Instituto Nacional de Estadística (INE).

CUADRO 2

Montevideo: Incidencia de la pobreza en la población y contribución a la pobreza, a la indigencia y a la población total, según grupos de barrios

\begin{tabular}{|c|c|c|c|c|c|c|c|c|}
\hline \multirow[t]{2}{*}{$\begin{array}{l}\text { Grupos de } \\
\text { barrios }^{\mathrm{a}}\end{array}$} & \multicolumn{2}{|c|}{$\begin{array}{c}\text { Incidencia de la pobreza } \\
\text { en la población de } \\
\text { cada barrio }^{\text {b }}\end{array}$} & \multicolumn{2}{|c|}{$\begin{array}{c}\text { Contribución de los grupos } \\
\text { de barrios al total de la } \\
\text { pobreza en Montevideo }\end{array}$} & \multicolumn{2}{|c|}{$\begin{array}{l}\text { Contribución de los grupos } \\
\text { de barrios al total de la } \\
\text { indigencia en Montevideo }\end{array}$} & \multicolumn{2}{|c|}{$\begin{array}{l}\text { Contribución de los grupos } \\
\text { de barrios al total de la } \\
\text { población de Montevideo }^{c}\end{array}$} \\
\hline & 1986-88 & $1995-97$ & 1986-88 & $1995-97$ & 1986-88 & $1995-97$ & 1985 & 1996 \\
\hline Total & 34,5 & 15,8 & 100,0 & 100,0 & 100,0 & 100,0 & 100,0 & 100,0 \\
\hline $1(\mathrm{~N}=3)$ & 66,7 & 45,0 & 9,4 & 14,2 & 14,1 & 21,4 & 4,8 & 6,5 \\
\hline $3(\mathrm{~N}=14)$ & 45,7 & 20,4 & 30,5 & 30,8 & 30,4 & 25,9 & 23,2 & 23,6 \\
\hline $4(\mathrm{~N}=15)$ & 29,1 & 9,7 & 20,2 & 13,2 & 14,4 & 7,9 & 22,3 & 20,6 \\
\hline $5(\mathrm{~N}=7)$ & 23,1 & 6,7 & 6,8 & 4,5 & 3,7 & 2,8 & 10,4 & 9,8 \\
\hline $6(\mathrm{~N}=6)$ & 14,7 & 4,0 & 5,3 & 3,1 & 3,2 & 3,9 & 12,8 & 11,7 \\
\hline $7(\mathrm{~N}=3)$ & 8,4 & 1,6 & 1,8 & 0,8 & 0,5 & 1,0 & 7,7 & 7,4 \\
\hline $8(\mathrm{~N}=2)$ & 4,5 & 1,3 & 0,4 & 0,2 & 0,5 & 0,7 & 3,0 & 3,0 \\
\hline $\begin{array}{l}\text { Barrios de los } \\
\text { grupos } 1,2 \text { y } 3\end{array}$ & 52,5 & 27,2 & 65,5 & 78,2 & 77,7 & 83,7 & 43,9 & 47,5 \\
\hline
\end{tabular}

Fuente: Cervini y Gallo (2001), a partir de la Encuesta Continua de Hogares del INE.

a Agrupación de barrios mediante el método multivariado cluster, a partir del ingreso per cápita del hogar, la proporción de adultos que completaron la enseñanza secundaria y el porcentaje de personas con atención en salud del Ministerio de Salud Pública.

b Elaboración propia a partir de datos de la Encuesta Continua de Hogares del INE.

c Elaboración propia a partir de datos del INE (1998).

CUADRO 3

Montevideo: Estructura barrial en 1996 por variaciones intercensales de población entre 1985-1996, según la densidad poblacional media de cada barrioa

\begin{tabular}{|c|c|c|c|c|}
\hline \multirow{2}{*}{$\begin{array}{l}\text { Tipo de barrio según variación } \\
\text { intercensal de población (1985-1996) }\end{array}$} & \multicolumn{4}{|c|}{ Densidad poblacional media del barrio } \\
\hline & Baja & Media & Alta & Total \\
\hline Barrios expulsores & 9,1 & 20,0 & 75,0 & 33,9 \\
\hline Barrios estables & 9,1 & 60,0 & 20,0 & 29,0 \\
\hline Barrios receptores & 81,8 & 20,0 & 5,0 & 37,1 \\
\hline Total & 100,0 & 100,0 & 100,0 & 100,0 \\
\hline Total de barrios & 22 & 20 & 20 & 62 \\
\hline
\end{tabular}

Fuente: Elaboración propia con datos del INE (1998).

a Tasas de variación intercensal 1985-1996: Barrios expulsores, menor de $-4 \%$; barrios estables entre $-4 \%$ y $+3 \%$; barrios receptores: mayor de $+3 \%$. Densidad bruta de la población en 1996: la densidad se considera baja hasta 6.000 hab. $/ \mathrm{km}^{2}, \mathrm{media}^{\mathrm{de}} 6.000 \mathrm{a} 10.000 \mathrm{hab} . / \mathrm{km}^{2}$, y alta de más de $10.000 \mathrm{hab} . / \mathrm{km}^{2}$. 
CUADRO 4

\section{Montevideo: Porcentaje de barrios según tasas de variación intercensal, ${ }^{a}$ por composición social e índice de situaciones de riesgo, 1996}

\begin{tabular}{lcccr}
\hline Barrios & $\begin{array}{c}\text { Barrios } \\
\text { expulsores }\end{array}$ & $\begin{array}{c}\text { Barrios } \\
\text { estables }\end{array}$ & $\begin{array}{c}\text { Barrios } \\
\text { receptores }\end{array}$ & Total \\
\hline $\begin{array}{l}\text { Composición } \\
\text { social del barrio }\end{array}$ & & & & \\
Baja & 4,8 & 22,2 & 69,6 & 33,9 \\
Media & 38,1 & 38,9 & 21,7 & 32,3 \\
Alta & 57,1 & 38,9 & 8,7 & 33,9 \\
Total & 100,0 & 100,0 & 100,0 & 100,0 \\
& & & & \\
Indice de riesgo & & & & \\
social del barrio & & & & \\
Bajo & 57,1 & 38,9 & 4,3 & 32,3 \\
Medio & 33,3 & 44,4 & 26,1 & 33,9 \\
Alto & 9,5 & 16,7 & 69,6 & 33,9 \\
Total & 100,0 & 100,0 & 100,0 & 100,0 \\
N & 21 & 18 & 23 & 62 \\
\end{tabular}

Fuente: Elaboración propia sobre la base de Kaztman (1999), de datos del VII Censo General de Población (INE, 1998).

\footnotetext{
a Las tasas de variación intercensal 1985-1996 se utilizan para clasificar los barrios en expulsores (tasa menor de $-4 \%$ ); estables (entre $-4 \%$ y $+3 \%$ ) y receptores (mayor de $+3 \%$ ). La composición social de los barrios se mide a partir del porcentaje de ocupaciones de alto estatus (profesionales, gerentes, técnicos, etc.), y el índice de comportamientos de riesgo surge de la suma estandarizada de los indicadores de riesgo (maternidad adolescente, insuficiencia educativa y jóvenes que no estudian, no trabajan ni buscan trabajo).
}

sociedad urbana que en el pasado reciente, cuando sus vínculos con el mercado de trabajo eran más fuertes, más estables y más protegidos, y componían un escenario más cercano a lo que Castel llamó "la sociedad asalariada". De hecho, en Montevideo los barrios con alta densidad de obreros industriales fueron bastante homogéneos en su composición, pero se trataba de una homogeneidad de carácter "virtuoso", fruto de un ensamble entre el mundo de la fábrica con el del vecindario, cuya armonía se manifestaba en una sociabilidad y una institucionalidad locales que fortalecían las solidaridades generadas en uno y otro ámbito. En los nuevos barrios pobres, en cambio, la mayor fragilidad de los lazos laborales y su correlato de mayor densidad de carencias limitan tanto la formación de redes de reciprocidad como las posibilidades de crear y mantener instituciones barriales propias, todo lo cual tiende a hacer más endeble el tejido social comunitario.

El tercer cuestionamiento tiene que ver con disparidades en el marco de referencia desde el cual los residentes de barrios pobres evalúan su situación. Los hogares que se establecieron de manera precaria en la periferia de la ciudad en el decenio de 1950 fueron resultado de desplazamientos de población de origen rural o de pequeños pueblos. Muchos de los migrantes enfrentaron ese cambio con expectativas de mejorar su calidad de vida, tanto por la conquista simbólica de una ciudadanía urbana, y el acceso real a consumos y servicios mucho más variados que los disponibles en su lugar de origen, como por las oportunidades ocupacionales que brindaba en esa época la expansión de mercados internos, cuya capacidad de absorción de empleo, estimulada por la sustitución de importaciones y la ampliación del aparato del Estado, permitió mantener abiertas importantes avenidas de movilidad social.

La escasa información disponible acerca de la conformación de barrios pobres a partir del decenio de 1980 arroja un panorama diferente. En primer lugar, se trata mayoritariamente de una población de origen urbano que se traslada desde otras zonas de la propia ciudad de Montevideo. ${ }^{4}$ En otras palabras, si la conformación de los asentamientos marginales de mediados del siglo XX fue impulsada por la fuerte atracción de las ciudades, la del decenio de 1980 en adelante está marcada por procesos de expulsión. Segundo, si lo característico del escenario que enfrentaban los pobres urbanos de la década de 1950 era la ampliación de vías de movilidad, lo que se destaca en la actualidad es el estrechamiento de esas vías. En tercer lugar, se debe tener en cuenta que, a la par con el aumento de la concentración territorial de los pobres, hubo movimientos de las clases medias altas y de las clases altas a barrios exclusivos, los que en algunos casos adoptaron el modelo de los condominios cerrados (Álvarez, 2004). Pero como la misma autora destaca, la magnitud del fenómeno de barrios exclusivos en Montevideo está muy lejos de la que exhiben otras grandes ciudades del Cono Sur, como San Pablo (Caldeira, 2000) o Buenos Aires (Svampa, 2002). De hecho, según Álvarez, en el año 2003 sólo había 10 condominios cerrados en el Gran Montevideo donde alojaban 315 familias. ${ }^{5} \mathrm{O}$ sea que, sin negar el aporte de los nuevos barrios exclusivos a los recientes procesos de fragmentación del espacio urbano, es posible afirmar que en Montevideo dicho aporte ha sido mucho más débil que en otras ciudades

\footnotetext{
4 Ya en 1984 quienes residían en esos asentamientos habían nacido en su mayoría $(93,5 \%)$ en áreas urbanas, y tres de cada cuatro en el mismo Montevideo (Cecilio, 1996).

${ }^{5}$ Compárese con las 434 comunidades cerradas habitadas en el 2000 por 13.500 familias en el Gran Buenos Aires, según informa Svampa (2002).
} 
sudamericanas. Por último, la heterogeneidad que aún existía en algunos barrios de composición social baja, o media baja, se vio alterada por procesos de salida de las familias con más recursos, las que buscaron eludir de ese modo los riesgos asociados al aumento de las tensiones e inseguridad en esas zonas. ${ }^{6}$ Todos estos movimientos contribuyeron a fragmentar la totalidad de la trama social urbana.

En suma, los actuales procesos de concentración espacial de la pobreza en Montevideo son más proclives que los del pasado a generar situaciones de aislamiento entre las clases y de vulnerabilidad a la exclusión social.

\section{2. ¿Por qué se ha hecho más homogénea la com- posición social de los barrios pobres de Mon- tevideo?}

Históricamente, muchas de las ciudades que han sufrido procesos significativos de concentración espacial de la pobreza suelen exhibir como antecedente una importante acentuación de la densidad urbana y de la movilidad social de su población. Ambos procesos, potenciados por una expansión del transporte y de las comunicaciones que facilita la separación de los lugares de trabajo y de residencia, suelen vincularse al aumento de las diferencias de precios de los terrenos entre las distintas zonas de la ciudad, así como al despliegue de una lógica inmobiliaria que distribuye a la población en el espacio urbano de conformidad con sus ingresos.

Pese a la evidencia de un aumento significativo de la concentración espacial de los pobres, Montevideo no ha mostrado ninguna de esas dos características. Cuando se compara su evolución desde mediados del siglo pasado con la de otras ciudades de la región, se destaca por su bajo crecimiento poblacional. Pese a ello, como lo señalan varios trabajos - Lombardi (1989), Retamoso (1999), Kaztman, Corbo y otros (2003)—, bajo la aparente quietud de su dinámica demográfica hubo, particularmente en los últimos 20 años, desplazamientos masivos de población, principalmente del centro a la periferia de la ciudad. ${ }^{7}$ Tampoco

\footnotetext{
6 En las entrevistas realizadas como parte del estudio sobre los recursos de las familias urbanas de bajos ingresos para enfrentar situaciones críticas (Zaffaroni, 1999) se documentan traslados de hogares que "escapan" de barrios a impulsos de lo que perciben como graves condiciones de inseguridad.

7 "En el marco de esta polarización, existen, sin embargo, contracorrientes en la localización de los hogares más vulnerables. Los estudios empíricos de Mazzei y Veiga (1985a, 1985b y 1986) de
}

hay pruebas que apoyen la hipótesis de una movilidad social importante. La escasa información disponible en este campo parece indicar más bien una alternancia entre períodos de estancamiento de la estructura social y períodos de movilidad descendente de importantes segmentos de las clases medias.

A juicio de los autores, la explicación más sustentable acerca del incremento de la concentración espacial de los pobres en Montevideo conjuga al menos tres factores: la insuficiente demanda de mano de obra de baja calificación, la liberalización del mercado de alquileres, y el repliegue de políticas públicas de vivienda en el contexto de un gasto social crecientemente absorbido por el pago de pensiones y jubilaciones. ${ }^{8}$ La combinación de estas fuerzas empujó a muchas familias a buscar solución a sus problemas habitacionales en los suelos urbanos más baratos, o simplemente a ocupar tierras donde construyeron viviendas precarias.

Con respecto a la demanda de mano de obra de baja calificación, se puede argumentar que las limitaciones generales en la capacidad de absorción de empleo no son nuevas en Uruguay. Ya en las etapas finales del período de sustitución de importaciones, la llamada "insuficiencia dinámica de la economía" era un rasgo al que los especialistas en estos temas apuntaban con preocupación. De modo que lo nuevo que introdujo la reciente ampliación de las fronteras de competitividad del país, así como el rápido giro hacia la incorporación de tecnología, fue una agudización tanto de insuficiencias dinámicas que ya se registraban en el mercado como de la brecha entre las situaciones de empleo de los calificados y los no calificados.

En ese escenario, la liberalización de alquileres colocó a una proporción creciente de los no calificados en situación de no poder pagar los arrendamientos ni

mediados de la década de los 80 encuentran que una parte de los asentamientos informales no se distribuyen en torno a la ciudad en forma de anillos, sino que tienden a localizarse como enclaves próximos a las oportunidades de trabajo. Las dos formas asumidas por esos enclaves son: o la localización próxima a los barrios ricos o la utilización de espacios en el centro de la ciudad en viviendas de mala calidad (Portes, 1989). El elemento determinante que une a ambas modalidades de ubicación residencial es la proximidad a zonas de generación de empleo. Sin embargo, al mantenimiento de los patrones de localización orientados por oportunidades laborales vinculadas a los servicios se contrapone una lógica inmobiliaria que, activada por los cambios en el precio de la tierra urbana, tiende a desplazar a los más pobres de las áreas de mayor densidad, así como de las cercanías de las áreas residenciales" (Kaztman, 1999). ${ }^{8}$ Entre los factores determinantes del rápido crecimiento de los asentamientos irregulares en Montevideo se debe incluir también la actitud general del sistema político hacia la ocupación de tierras. 
conseguir avales para suscribir contratos de alquiler, cuyo cumplimiento, por otra parte, era incierto. Un estudio publicado en 1994 ya advertía sobre la notable expansión de los asentamientos irregulares y sobre el hecho de que una parte significativa de sus habitantes provenía de "casas o apartamentos", lo que llevaba a los autores a suponer que la ocupación de terrenos surgió como opción ante la imposibilidad de continuar habitando en viviendas que formaban parte del mercado "formal", situación que aparentemente se agravaba en los casos de hogares jóvenes de reciente formación (Cecilio, 1996).
En suma, en el marco de las políticas habitacionales existentes, de las diferentes rentas del suelo y de las modalidades de especulación inmobiliaria, los procesos mencionados generaron un desplazamiento progresivo de familias pobres a los barrios más baratos de la ciudad o, en el caso de los asentamientos, a la ocupación de terrenos sin costo. En estos aspectos, la literatura sobre el tema en Uruguay concuerda en afirmar que el factor singular más importante para explicar los actuales niveles de segregación residencial en Montevideo ha sido el de la pauperización e inestabilidad ocupacional de un gran número de asalariados.

\section{III}

\section{Las tendencias del empleo}

Al igual que en otras ciudades, la nueva pobreza en Montevideo está fuertemente anclada en lo que hoy se considera uno de los rasgos dominantes de los modernos mercados laborales, a saber, la debilidad de sus vínculos con las personas de escasa calificación. Durante el proceso de sustitución de importaciones, la solidez de esos vínculos bastó para que una significativa proporción de trabajadores, en particular los que se incorporaron a las industrias entonces emergentes, pudieran planificar sus vidas, construir sus identidades y elaborar expectativas razonables de movilidad social en torno al trabajo. ${ }^{9}$

Esas posibilidades y proyectos son hoy día poco viables. Algunas cifras sintetizan las transformaciones en el mercado de trabajo que avalan la afirmación anterior. Entre 1970 y 1999, el Estado redujo casi a la mitad (del 28\% al 16\%) su presencia en ese mercado. Algo similar sucedió con la industria, que en 1970 concentraba el $32 \%$ de la fuerza de trabajo y en el 2002 sólo alcanzaba al $16 \%$. Paralelamente se registró un notable crecimiento de la población económicamente activa (PEA) femenina, cuyas tasas de participación subieron en esos treinta años del $27,5 \%$ al $52,55 \%$, y que, a falta de un dinamismo concomitante en la ge-

\footnotetext{
${ }^{9}$ Gran parte de la integración social predominante históricamente en Uruguay se basó en la naturaleza del llamado modelo de sustitución de importaciones, fruto de una alianza que abarcaba aproximadamente un $80 \%$ de la población y que se apoyaba en un triángulo antishumpeteriano entre el Estado, la burguesía industrial protegida y sus trabajadores.
}

neración de empleo, favorecieron el alza de las tasas de desempleo, el empeoramiento de las condiciones de trabajo y la disminución de los salarios. A partir de 1980 irrumpieron grandes capitales en el comercio y en los servicios, desplazando a proporciones significativas de una pequeña burguesía semiformal que había operado como importante fuente de generación de clases medias independientes. También a partir de la segunda mitad del decenio de 1990 hubo un aumento de crisis recurrentes de corto plazo.

Los procesos recién resumidos repercutieron en el aumento del desempleo y en la generación de inestabilidad, precariedad y baja productividad, fenómenos propios del sector informal que causaron un progresivo distanciamiento de los trabajadores de menor calificación con respecto a aquellos con mayor calificación (Kaztman, Corbo y otros, 2003; PNUD, 2001). ${ }^{10}$

Estos rasgos de la inserción laboral constituyen el antecedente singular más importante no sólo del endurecimiento de la pobreza en la generación presente, sino también del reforzamiento de los mecanismos de su reproducción intergeneracional. Ello se debe a que los adultos que no cuentan con habilidades y destrezas

\footnotetext{
${ }^{10}$ Se podría contraargumentar que la crisis del mundo laboral, y el consecuente aumento de la incertidumbre con respecto al bienestar, afecta a todos los estratos sociales. Sin embargo, indudablemente aquellos con mayor capital humano acumulado están en mejor posición que el resto para aprovechar las oportunidades que brinda una estructura productiva crecientemente organizada alrededor del conocimiento y que incorpora innovaciones tecnológicas en forma más y más acelerada.
} 
como para eludir la inestabilidad y la precariedad laboral, difícilmente podrán transferir a sus hijos los recursos en capital físico, humano y social que demandará su desarrollo integral en las sociedades posindustriales.

Por su fuerte impacto sobre las características de las clases populares urbanas, vale la pena detenerse un poco más en la evolución de las actividades industriales en Montevideo. Además de compartir la declinación general que registraron estas actividades en el país, la ciudad fue perdiendo primacía en ellas. Mientras que en 1960 concentraba el $78 \%$ de la producción industrial bruta, a principios de la década de 1990 la cifra era de
60\% (Becker, Jager y Raza, 2001). El doble proceso —la declinación general de la actividad y la pérdida de primacía industrial- afectó fuertemente la capacidad de absorción de empleo de las fábricas que, instaladas en distintos barrios de la capital, se nutrían básicamente de trabajadores del entorno. Ese reclutamiento zonal había favorecido la formación de circuitos densos de relaciones entre las familias, los vecinos y los compañeros de trabajo. ${ }^{11}$ Con el ocaso del modelo de sustitución de importaciones gran parte de las industrias cerraron sus puertas, los empleos estables como los del sector público disminuyeron y Montevideo perdió parte de la supremacía que ostentaba en términos industriales.

\section{IV}

\section{Segregación residencial y empleo}

Siempre que se plantean relaciones entre características contextuales (barrios segregados) y características individuales (situación de empleo, precariedad laboral) es conveniente mantener una mirada crítica sobre la dirección de las líneas de causalidad, sin perder de vista la posibilidad de movimientos inversos allí donde las supuestas causas son afectadas por las supuestas consecuencias. En el caso de las relaciones entre la situación de empleo y la ubicación de la vivienda, la línea de causalidad que se examina con mayor frecuencia es consonante con la idea que asigna una mayor probabilidad de fijar su residencia en los vecindarios más pobres a los que tienen mayores problemas en el mercado laboral. Dado lo razonable de esa asociación, no es de extrañar que la concentración de poblaciones de baja calificación en ciertos vecindarios sea usualmente interpretada más como consecuencia que como causa de lo que le pasa a las personas en el mercado de trabajo.

La evidencia proporcionada por los estudios que examinan el rápido crecimiento de los asentamientos irregulares en los bordes de la ciudad de Montevideo apuntala esa interpretación. En ellos se señala que la incapacidad para pagar alquileres, obtener garantías para contratos de arrendamiento o, en algunos casos, para cubrir los impuestos de pequeñas propiedades, son los causantes singulares más importantes del desplazamiento masivo de familias jóvenes desde zonas relativamente centrales de la ciudad hacia otras más periféricas. A ese desplazamiento, que alimenta la con- centración territorial de la pobreza, se suma una homogeneización creciente de la composición social de los barrios periféricos, que resulta de las crecientes dificultades de empleo enfrentadas por los que ya residían en esas zonas.

Pero aun admitiendo que las oportunidades de empleo son causas importantes tanto de los desplazamientos hacia los barrios que concentran pobres como del "nuevo" empobrecimiento de sus antiguos residentes, también cabe reconocer que, una vez que las personas se establecen o permanecen en esos barrios de pobreza más concentrada y homogénea, sus eventuales vínculos con el mercado de trabajo van a ser afectados por factores y procesos propios de entornos con altas densidades de carencias. Los efectos del contexto de residencia se van a revelar con mayor nitidez en las generaciones socializadas en esos vecindarios, para las cuales la influencia del barrio claramente antecede a sus intentos de inserción laboral.

Los cuadros que siguen exhiben distribuciones de algunos indicadores sustitutivos de la inestabilidad (la tasa de desempleo), de la informalidad (el trabajo por cuenta propia) y de la precariedad laboral (la falta de cobertura de salud), que afectan a residentes de distintos segmentos censales de Montevideo según su

\footnotetext{
${ }^{11}$ Nótese, además, que la estabilidad del empleo fabril estimulaba los intentos de los obreros de radicar su vivienda en las cercanías de los lugares de trabajo.
} 
Montevideo: Tasa de desempleo según el contexto educativo del segmento censal, por edad, sexo y educación de los residentes, 1996

\begin{tabular}{|c|c|c|c|c|c|c|c|c|c|c|}
\hline \multirow{2}{*}{\multicolumn{2}{|c|}{$\begin{array}{l}\text { Edad } \\
\text { y educación }\end{array}$}} & \multicolumn{9}{|c|}{ Contexto educativo del segmento } \\
\hline & & \multicolumn{3}{|c|}{ Bajo } & \multicolumn{3}{|c|}{ Medio } & \multicolumn{3}{|c|}{ Alto } \\
\hline Edad & Educación & Hombre & Mujer & Total & Hombre & Mujer & Total & Hombre & Mujer & Total \\
\hline \multirow{7}{*}{15 a 29} & Primaria incompleta & 22,8 & 39,0 & 27,0 & 22,2 & 33,4 & 25,6 & 17,6 & 24,1 & 19,7 \\
\hline & Primaria completa & 21,6 & 33,7 & 25,3 & 23,5 & 32,3 & 26,2 & 19,1 & 26,9 & 21,6 \\
\hline & 7 y 8 años & 19,6 & 29,9 & 23,5 & 20,2 & 26,6 & 22,7 & 17,5 & 21,5 & 19,0 \\
\hline & 9 y 10 años & 17,2 & 24,3 & 20,3 & 16,0 & 22,6 & 19,0 & 15,2 & 19,4 & 17,1 \\
\hline & 11 años & 15,6 & 20,9 & 18,2 & 13,4 & 20,5 & 16,8 & 13,8 & 17,3 & 15,5 \\
\hline & 12 y más & 12,9 & 16,3 & 14,8 & 13,6 & 15,6 & 14,8 & 12,7 & 16,1 & 14,6 \\
\hline & Total & 19,6 & 27,7 & 22,7 & 18,1 & 22,4 & 20,0 & 14,7 & 17,8 & 16,2 \\
\hline \multirow{7}{*}{30 y más } & Primaria incompleta & 13,0 & 16,0 & 14,1 & 10,6 & 13,6 & 11,8 & 7,5 & 9,8 & 8,5 \\
\hline & Primaria completa & 11,2 & 16,9 & 13,4 & 10,1 & 14,3 & 11,8 & 7,2 & 10,0 & 8,4 \\
\hline & 7 y 8 años & 11,0 & 16,0 & 13,1 & 9,2 & 14,3 & 11,4 & 6,4 & 10,1 & 8,0 \\
\hline & 9 y 10 años & 8,5 & 14,0 & 10,9 & 7,1 & 11,3 & 9,0 & 5,1 & 8,8 & 6,8 \\
\hline & 11 años & 8,6 & 11,9 & 10,1 & 6,2 & 9,0 & 7,6 & 4,8 & 7,0 & 6,0 \\
\hline & 12 y más & 7,2 & 8,4 & 7,7 & 4,6 & 5,2 & 4,9 & 2,4 & 4,2 & 3,3 \\
\hline & Total & 10,7 & 15,0 & 12,4 & 8,0 & 10,8 & 9,3 & 4,3 & 6,6 & 5,4 \\
\hline \multirow{7}{*}{ Total } & Primaria incompleta & 15,1 & 19,4 & 16,5 & 12,0 & 15,1 & 13,2 & 8,2 & 10,5 & 9,2 \\
\hline & Primaria completa & 15,0 & 21,9 & 17,5 & 13,7 & 17,6 & 15,2 & 9,7 & 12,3 & 10,8 \\
\hline & 7 y 8 años & 15,2 & 22,4 & 18,0 & 14,0 & 19,1 & 16,0 & 10,8 & 13,7 & 11,9 \\
\hline & 9 y 10 años & 11,9 & 18,2 & 14,7 & 10,1 & 15,1 & 12,4 & 8,3 & 12,1 & 10,0 \\
\hline & 11 años & 11,5 & 16,0 & 13,6 & 8,7 & 12,9 & 10,8 & 7,7 & 9,9 & 8,8 \\
\hline & 12 y más & 9,0 & 11,5 & 10,2 & 7,1 & 8,6 & 7,9 & 5,1 & 7,9 & 6,5 \\
\hline & Total & 14,0 & 19,4 & 16,1 & 11,1 & 14,3 & 12,5 & 7,2 & 9,8 & 8,5 \\
\hline
\end{tabular}

Fuente: Elaboración propia con datos no publicados del proyecto Activos y estructura de oportunidades (Kaztman, 1999).

composición social. Dado que el censo no investiga el ingreso de los hogares, la definición operacional de la composición social de los segmentos censales se basó en el nivel educativo medio de los hogares que residen en ellos. ${ }^{12}$ Los datos provienen del censo de población y vivienda de 1996 y, por ende, cubren la totalidad de la población económicamente activa de la ciudad.

El cuadro 5 presenta la tasa de desempleo, considerada en este caso como una variable sustitutiva de la inestabilidad de la situación de empleo, para los

\footnotetext{
${ }^{12}$ La construcción de este indicador se hizo en dos etapas. En la primera se calculó para cada segmento censal el porcentaje de hogares con nivel educativo bajo, clasificando como tales a los hogares en los cuales el promedio de años de estudio de sus miembros mayores de 18 años no superaba el equivalente a educación primaria incompleta (menos de seis años de educación). En la segunda, una vez ordenados los 1.032 segmentos censales de la ciudad, según el porcentaje de hogares con bajo nivel educativo se procedió a dividir la distribución en deciles. Posteriormente, los deciles se agruparon en tres categorías. El "contexto educativo bajo" reúne al $30 \%$ de los deciles que tienen mayor porcentaje de hogares con baja educación; el "contexto educativo medio" aglutina a los cuatro deciles intermedios y el "contexto educativo alto", al 30\% de los deciles con menor cantidad de hogares poco educados.
}

segmentos censales de Montevideo clasificados en tres categorías, según el porcentaje de hogares con bajo nivel educativo. La información se presenta desagregada según la edad, el sexo y los años de estudio completados por los residentes.

Del cuadro se desprende que el comportamiento del desempleo varía sistemáticamente en función inversa a los niveles de educación medios utilizados para caracterizar la composición social de los segmentos censales, y que ello ocurre con independencia del sexo, la edad y la educación de los sujetos. ${ }^{13}$

Reflexiones similares surgen de los cuadros 6 y 7 . Con ellos buscamos estimar la distribución barrial de la actividad informal, a través del trabajo por cuenta propia, y de la precariedad laboral, a través de la ausencia de protección legal de la salud. Aun siendo imperfectos, los controles por nivel educativo de los individuos permiten una aproximación a la puesta a

\footnotetext{
13 Nótese que los intervalos entre los años de estudio de las personas son lo suficientemente estrechos como para verificar la posibilidad de que la variable dependiente esté siendo afectada por variaciones dentro de cada intervalo.
} 
CUADRO 6

Montevideo: Porcentaje de ocupados por cuenta propia, según el contexto educativo del segmento y los años de educación del ocupado, ${ }^{a} 1996$

\begin{tabular}{lrrrr}
\hline \multirow{2}{*}{$\begin{array}{l}\text { Educación del } \\
\text { ocupado }\end{array}$} & \multicolumn{5}{c}{ Contexto educativo del segmento } \\
\cline { 2 - 5 } & Bajo & Medio & Alto & Total \\
\hline Menos de 6 años & 24,8 & 23,4 & 20,5 & 23,8 \\
6 años & 18,9 & 18,0 & 16,9 & 18,3 \\
7 y 8 años & 15,5 & 14,6 & 12,8 & 14,6 \\
9 y 10 años & 13,5 & 11,7 & 8,9 & 11,2 \\
11 años & 10,8 & 8,6 & 6,5 & 8,0 \\
12 años o más & 8,5 & 5,1 & 3,0 & 4,1 \\
Total & 17,0 & 12,6 & 7,1 & 11,9 \\
\hline
\end{tabular}

Fuente: Elaboración propia con datos no publicados del proyecto Activos y estructura de oportunidades (Kaztman, 1999).

a Excluye directivos de empresa, profesionales y técnicos.

CUADRO 7

\begin{abstract}
Montevideo: Porcentaje de empleados privados sin cobertura de salud o con atención en el Ministerio de Salud Pública, ${ }^{a}$ según el contexto educativo del segmento y los años de educación del ocupado, 1996
\end{abstract}

\begin{tabular}{lrrrr}
\hline \multirow{2}{*}{$\begin{array}{l}\text { Educación del } \\
\text { ocupado }\end{array}$} & \multicolumn{5}{c}{ Contexto educativo del segmento } \\
\cline { 2 - 5 } & Bajo & Medio & Alto & Total \\
\hline Menos de 6 & 37,5 & 25,4 & 18,3 & 31,0 \\
6 años & 34,6 & 23,7 & 18,0 & 28,1 \\
7 y 8 años & 27,5 & 19,1 & 14,3 & 21,2 \\
9 y 10 años & 18,8 & 11,1 & 7,5 & 11,9 \\
11 años & 13,4 & 7,9 & 4,9 & 7,6 \\
12 años o más & 11,3 & 5,7 & 3,6 & 5,0 \\
Total & 27,6 & 14,7 & 7,4 & 16,2 \\
\hline
\end{tabular}

Fuente: Elaboración propia con datos no publicados del proyecto Activos y estructura de oportunidades (Kaztman, 1999).

a De conformidad con la legislación vigente, los empleados del sector privado generan derechos de atención en salud en instituciones de asistencia médica colectiva (IAMC). El hecho de no contar con esta atención, y encontrarse sin cobertura médica o con atención en el Ministerio de Salud Pública (MSP), da cuenta de aquellos ocupados que podrían no estar registrados en la seguridad social.

prueba de un efecto causal del contexto sobre los individuos. Pero independientemente de su interpretación final, los resultados estimulan interrogantes como el siguiente: ¿cuáles son los mecanismos que intervienen para que, por ejemplo, personas que completaron 11 años de estudios (única categoría de educación de las presentadas en el cuadro que cubre un solo año), sean ellos jóvenes o adultos (y en el caso del desempleo, sean hombres o mujeres), y que residen en barrios cuya composición social revela alta concentración de caren- cias, muestren mayores tasas de desempleo, mayores porcentajes de trabajadores por cuenta propia y menor cobertura de salud que las personas con el mismo nivel de estudios que residen en otros barrios?

Como recién se mencionó, la explicación de estas asociaciones no es simple, particularmente en lo que se refiere a la dirección de la causalidad. Por un lado, se puede argumentar que, con independencia del nivel de educación que hayan alcanzado, las personas con mayor propensión al desempleo tenderán a concentrarse en los barrios más pobres. Las regularidades empíricas observadas serían interpretadas entonces en términos de un proceso de selección implícito en la relación entre la pobreza del barrio y el vínculo de sus residentes con el mercado de trabajo. Desde ese punto de vista, en los barrios con mayores desventajas se acumularían los "perdedores" del sistema, aquellos que por una u otra razón no consiguen establecer un vínculo estable, protegido y redituable con el mundo laboral. Y que, al no disponer de recursos para cubrir los costos de vivir en otros lugares de la ciudad, se ven obligados a desplazarse con sus familias a las áreas marginales. De ser así, las diferencias encontradas entre los residentes de los distintos barrios no deberían atribuirse a la influencia de contextos que socializan o limitan oportunidades en forma diferenciada a los vecinos, sino simplemente a la agregación territorial de aquellos que comparten experiencias de fracasos en el mundo laboral.

Por otro lado, también se puede argumentar en el sentido opuesto, es decir, que la dirección causal va desde las características del contexto barrial a la situación de empleo de los residentes. Al respecto, resulta oportuno presentar un antecedente empírico que permite afinar la interpretación del peso relativo de una u otra de las posibles líneas de causalidad que ligan territorio y empleo. Los datos del cuadro 8 procuran abrir esa posibilidad.

CUADRO 8

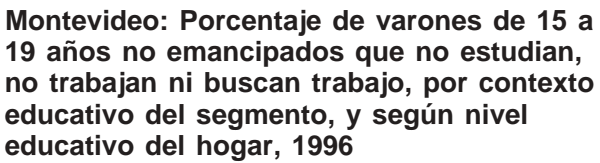

\begin{tabular}{lcccc}
\hline \multirow{2}{*}{$\begin{array}{l}\text { Nivel educativo } \\
\text { del hogar }\end{array}$} & \multicolumn{5}{c}{ Contexto educativo del segmento } \\
\cline { 2 - 5 } & Bajo & Medio & Alto & Total \\
\hline Hasta 6 años & 28,2 & 24,9 & 19,1 & 26,3 \\
Mas de 6 hasta 9 & 26,2 & 23,3 & 16,1 & 23,1 \\
Mas de 9 años & 21,9 & 18,1 & 12,5 & 15,5 \\
Total & 26,8 & 22,0 & 13,8 & 21,4 \\
\hline
\end{tabular}

Fuente: Elaboración propia con datos no publicados del proyecto Activos y estructura de oportunidades (Kaztman, 1999). 
El cuadro presenta la situación de jóvenes de 15 a 19 años que todavía viven en su hogar de origen y que no tienen afiliación con instituciones como las del mundo del trabajo y las educativas, que resultan centrales para su inserción en el mundo adulto. Se trata de los jóvenes que no trabajan, no estudian ni buscan empleo. Para nuestros propósitos, lo interesante del indicador es que, por su edad, se puede asumir razonablemente que en la población a que hace referencia existe una alta proporción de adolescentes y jóvenes que han nacido o se han socializado en los barrios donde residen, y que no han tomado ellos mismos la decisión de radicarse en esas zonas. Por ende, la comprobación de regularidades similares a las anteriores en estos grupos etarios restaría fortaleza a la dirección de causalidad que procura explicar las características del lugar de residencia por los problemas de inserción en el mercado. En el cuadro se considera el nivel educativo de los padres, habida cuenta de que esa variable ha probado ser uno de los predictores más potentes de la desafiliación institucional de los adolescentes y jóvenes (CEPAL, 1997; MEMFOD, 2002).

$\mathrm{Al}$ igual que en los casos anteriores, los resultados muestran una relación negativa, estadísticamente significativa, entre el nivel socioeconómico medio del barrio donde los jóvenes residen y la incidencia de la desafiliación institucional, cualquiera sea el nivel educativo de los padres. Cabría considerar aquí también, sin embargo, la posibilidad de que la misma configuración de recursos que determinó la localización de los padres en barrios pobres pueda haber incidido en los hijos a través de la socialización familiar. Si ese fuera el caso, estaríamos nuevamente en presencia de una relación espuria entre entorno y comportamientos, con la diferencia de que esta vez estaría intermediada por las familias. Abona este argumento el hecho de que el nivel educativo de los padres efectivamente incide en la desafiliación institucional de los hijos. En cambio, lo contradice el hecho de que, al comparar las diferencias explicadas por una y otra variable, se encuentra que el efecto de la composición social del vecindario parece ser más importante que el efecto del nivel educativo de la familia para explicar las variaciones en la desafiliación de los jóvenes.

Con estos antecedentes empíricos, pasemos ahora a examinar los mecanismos que podrían activarse en barrios con altas concentraciones de pobreza y que afectarían el tipo de vínculo que establecen sus residentes con el mercado laboral.

\section{1. ¿Cuáles son los factores asociados a la com- posición social de los barrios que pueden mediatizar el acceso de los residentes al mer- cado de trabajo?}

Antes de analizar los distintos mecanismos asociados a las condiciones de vida en barrios con altas concentraciones de pobreza - examen que ayuda a explorar sus efectos sobre el empleo- conviene considerar brevemente uno de los interrogantes básicos que surge cuando se pretende explicar comportamientos de personas por las características de los barrios donde residen: ¿cuáles son los factores que determinan la mayor o menor susceptibilidad de las personas a las influencias del entorno social del lugar donde habitan? Una primera aproximación a la respuesta es separar las condiciones que tienen que ver con características globales y analíticas de los barrios, de aquellas que guardan relación con características de los individuos que residen en ellos.

Con respecto a las primeras, hay múltiples atributos de los barrios que favorecen su incidencia sobre los residentes. El más general es la cercanía física. En efecto, cuando se la compara con otras tramas sociales que podrían operar como fuentes de reconocimiento, de sociabilidad y de formación de identidades - como, por ejemplo, las que se construyen en el lugar de trabajo, en el lugar de estudio y en las asociaciones e instituciones en las que participan los residentes - la trama social del barrio se caracteriza por ser la más próxima a los espacios privados de las personas. Saravi (2004) grafica muy bien esta idea cuando afirma que “...el barrio constituye $[\ldots]$ el primer encuentro público al abrirse la puerta de lo privado".

Si bien la proximidad física es un rasgo que facilita la incidencia de la trama social del barrio sobre las personas, el signo de esa incidencia variará según otras características. Las siguientes parecen ser las tres más significativas. En primer lugar, importa el nivel de seguridad y el tono general de la convivencia vecinal. Con respecto a sus efectos sobre la formación de las actitudes y expectativas de los residentes, Saravi (2004, p. 35) afirma que “...el clima - de seguridad o inseguridad, violencia o amistad, reconocimiento mutuo o indiferencia- que predomine moldeará las características de las interacciones y relaciones que se construyen en los espacios públicos locales". Un segundo factor significativo es el estatus social del barrio. Los habitantes de las ciudades suelen tener imágenes claras de la ubicación de su barrio en una escala general de prestigio de los barrios de la ciudad. Aunque los 
residentes de algunos barrios pueden ser más sensibles que otros a criterios tales como el nivel de desorden social, el criterio más general para ese ordenamiento es el nivel socioeconómico medio de los hogares que en ellos residen. Para los vecinos de un barrio, y dependiendo de sus márgenes de elección, esas imágenes tendrán mayor o menor peso en las decisiones que tomen para fijar su residencia, en el grado de apertura a las influencias de su entorno social inmediato, así como en la mayor o menor importancia que asignen a la pertenencia al barrio en su configuración de identidad. Un tercer factor que ayuda a entender la incidencia del barrio en los hábitos, comportamientos y expectativas de los residentes es su trama socioinstitucional. Cuanto más densa sea dicha trama, mayor será la probabilidad que los patrones normativos locales intervengan eficazmente en la regulación del comportamiento público de los vecinos.

Con respecto a las características individuales, las diferencias en la receptividad de las personas a las influencias de su entorno vecinal dependerán, entre otros factores, de sus "valencias libres". Cuanto más estrechos sean los ámbitos disponibles para satisfacer las necesidades de reconocimiento, identidad y pertenencia, mayor será la susceptibilidad a las influencias de la trama vecinal y la propensión a modificar o incorporar hábitos y expectativas como resultado de interacciones con vecinos. De ser así, cabría esperar que la influencia de los barrios sobre los comportamientos fuera mayor en los sectores de la población urbana más vulnerables a la exclusión social, justamente porque el proceso de exclusión alude a una progresiva reducción de otras fuentes de pertenencia, reconocimiento e identidad ajenas al barrio.

Estas breves observaciones sobre algunos de los aspectos que pueden mediatizar la influencia del contexto vecinal sobre el comportamiento alertan acerca de la conveniencia de comprobar empíricamente cualquier supuesto sobre un impacto uniforme de los barrios sobre las personas. Más bien, este campo de estudio parece requerir todavía prolongados esfuerzos encaminados a elaborar y pulir marcos conceptuales basados en una también importante acumulación de estudios de casos. Con estas advertencias, pasaremos al análisis de los mecanismos.

\section{Mecanismos de intermediación entre contex- tos barriales y comportamientos individuales}

Existe una serie de mecanismos, algunos de los cuales ya han sido examinados extensamente en la literatura especializada, que intervienen entre aspectos del barrio y los comportamientos de sus residentes. Aun cuando los mecanismos que se comentarán a continuación no coinciden con los señalados por Small y Newman (2001), al presentarlos utilizaremos la distinción que hacen esos autores entre mecanismos instrumentales y mecanismos de socialización.

\section{a) Mecanismos instrumentales}

Los mecanismos instrumentales son las distintas vías a través de las cuales las condiciones del barrio pueden limitar la acción individual. Bajo esta categoría incluimos los siguientes: la distancia a los lugares de trabajo y los costos en tiempo y dinero asociados al transporte, las oportunidades locales de empleo, las posibilidades de acumular un capital social útil al logro de empleo, las limitaciones a la movilización de la fuerza de trabajo familiar que plantea la inseguridad ambiental, y la reacción de los potenciales empleadores frente al eventual reclutamiento de residentes de estos barrios.

Si las concentraciones de hogares pobres se producen en barrios ubicados en la periferia de las ciudades, los problemas de transporte asumen para sus residentes una dimensión concordante con el costo de la movilización como proporción de los ingresos. En estudios de casos sobre jóvenes pobres de Montevideo se observa que dichos costos, además de constituir una pesada limitación a la búsqueda de empleo, tienen una incidencia gravitante en la decisión de aceptar trabajos cuyas remuneraciones son muy bajas una vez deducido el precio de los traslados. Al respecto, se debe tener en cuenta que el fuerte desplazamiento hacia los servicios personales de la demanda urbana de trabajadores no calificados se concentró en los barrios en que reside la población con mayores recursos, donde los valores de la propiedad y del arrendamiento de viviendas son los más elevados de la ciudad. Las dificultades que por ese motivo enfrentan las personas poco calificadas para establecer sus lugares de residencia cerca de sus potenciales lugares de trabajo repercuten sobre sus posibilidades de empleo a través de los costos de transporte y del tiempo que toman los traslados. ${ }^{14}$ De todos modos, alrededor de los vecindarios de clase media alta y de clase alta de Montevideo es posible observar manchones de pobreza, resultado seguramente

\footnotetext{
${ }^{14}$ Suárez (2004). Según dicha autora, "muchos entrevistados comentaron que se contentaban con hacer trabajos de tipo changas en el mismo barrio o cerca del mismo, porque 'para salir a buscar trabajo hay que tener plata'; 'uno no puede pagar todos los días un colectivo para buscar trabajo' ...".
} 
de elaboradas estrategias de los hogares de menores recursos para compatibilizar vivienda con trabajo.

Un segundo mecanismo, cuyo impacto varía con el nivel de concentración de pobreza en los barrios, se relaciona con la presencia de pequeños talleres industriales o reparadores y de comercios que proveen distintos tipos de servicios. En los barrios populares que reunían una proporción relativamente alta de trabajadores estables, los adolescentes y jóvenes se beneficiaban de la presencia de estas iniciativas, las que oficiaban de vías importantes para sus primeras experiencias de trabajo como cadetes, asistentes, aprendices o ayudantes en distintas tareas. Nótese que, en esos casos, el reconocimiento de la posibilidad de réditos potenciales asociados a la existencia de oportunidades laborales en el vecindario brindaba a las familias una motivación adicional para invertir en la construcción de capital social local, dada la expectativa realista de que ese capital se materializara en empleos concretos.

Una de las consecuencias de la pérdida de dinamismo industrial, la apertura de importaciones de todo tipo de electrodomésticos baratos y la creciente presencia del gran capital en los supermercados, fue la gradual desaparición de muchos de estos pequeños negocios y talleres. Lo que se observa - tanto en los viejos barrios obreros como en los que se van formando en la periferia de la ciudad - son, por un lado, numerosas ofertas individuales de productos usados o de alimentos de producción casera, ofertas que muchas veces se concentran en ferias localizadas en distintos puntos de esos barrios, y por otro lado, microemprendimientos familiares con infraestructura mínima que funcionan dentro de las viviendas o como extensiones de estas. En ese panorama son pocos los negocios que exhiben un nivel de formalidad y una dinámica suficientes como para necesitar más mano de obra que aquella movilizada dentro de los hogares como trabajadores familiares no remunerados.

En relación a los réditos del capital social vinculados a la obtención de trabajo, el aumento de la segregación espacial tiene otra consecuencia negativa. Esto porque la construcción del otro capital social —el de los lazos débiles, en la denominación de Granovetter (1985) - que para los pobres suele ser una fuente vital de información y de contactos útiles para insertarse en el mundo laboral, se ve crecientemente obstruida por el distanciamiento físico y el estrechamiento de los ámbitos de interacción con otras clases que acompañan ese proceso de segregación. ${ }^{15}$

${ }^{15}$ Durante el período de expansión del empleo público hubo redes de capital social basadas en el clientelismo político que penetraron
Un cuarto mecanismo instrumental tiene que ver con las limitaciones que plantea la inseguridad pública a la movilización de la fuerza de trabajo del hogar. El temor a las agresiones, a los robos y a la exposición de los niños a influencias indeseadas congela recursos de los hogares que podrían utilizarse para la generación de ingresos, moldeando sus estrategias de supervivencia. El clima de inseguridad influye en la elección de ocupaciones, en las restricciones horarias al tránsito por espacios públicos que los vecinos han dejado de controlar, en la necesidad de asignar recursos humanos de la familia al cuidado de los bienes de la vivienda, o de los niños que no pueden quedar solos y que deben ser acompañados a los lugares de estudio o de recreación.

Finalmente, el aumento de la distancia física y social entre las poblaciones de los vecindarios pobres y el resto de la ciudad también modifica la forma en que las clases sociales se miran unas a otras. Esas transformaciones resultan de la confluencia de dos procesos. Por un lado, a medida que se reducen las oportunidades de sociabilidad entre las clases, aquellas que son parte de los circuitos principales de la sociedad urbana van perdiendo su capacidad para "colocarse en el lugar de la otra" (empatía). Estas circunstancias favorecen mayores umbrales de tolerancia tanto a las desigualdades como a las diversas manifestaciones de la miseria en las calles de la ciudad. Por otro lado, el aumento de la densidad de carencias en los barrios pobres produce fisuras en su tejido social, por las que germinan las subculturas marginales. Los consecuentes estados de desorden afectan la imagen pública de esos barrios. Aquellos cuyos patrones de comportamientos son percibidos por el resto de la sociedad urbana como más exóticos y peligrosos se catalogan de "zonas rojas". La combinación de ambos procesos favorece la creación de estigmas. Estas imágenes estereotipadas llegan a gravitar pesadamente en la identificación colectiva de aquellos que, expuestos a experiencias similares de discriminación, van descubriendo una penosa comunidad de problemas y de destinos con sus vecinos. Para nuestros propósitos, importa destacar que dichas imágenes, que imponen su sello negativo a ciertas zonas de la ciudad, también tiñen los criterios que

profundamente en los barrios pobres de Montevideo, ampliando las oportunidades de inserción laboral de sus residentes. Debilitado su margen de maniobra por las crecientes presiones por ajustar las cuentas fiscales, los políticos que manejaban esas redes fueron perdiendo los recursos necesarios para mantener tales prácticas. Véase en Rama (1971) y Luna (2004) el análisis de los procesos que acompañaron el apogeo y el ocaso (o cambio de naturaleza) del clientelismo político en Uruguay. 


\section{Recuadro}

El tema de los costos que implica para los hogares pobres el clima de inseguridad de sus barrios ha sido escasamente tratado en la literatura, por lo que vale la pena dar algunos pocos ejemplos de cómo lo viven los afectados. Una entrevistada en un barrio desfavorecido del Gran Buenos Aires manifiesta, refiriéndose a la ocupación que tiene (Suárez, 2004):

"Son los trabajos que puedo hacer... Con hijos es difícil hacer otra cosa. Ellos me necesitan en la casa... si no estás, andá a saber en qué se meten... Antes de soltera trabajé en un hotel en Once, pero ahora no me puedo ir todo el día”.

Problemas similares plantean residentes de barrios pobres de Montevideo (Zaffaroni, 1999):

- "Cuando voy al trabajo tengo que dejar a los chiquilines toda la tarde encerrados, no los puedo dejar acá solos. Los gurises andan por ahí drogados. Si tenemos que salir salgo yo o sale Julio, los dos juntos no podemos. Si dejás acá solo, cuando venís no tenés ni las ventanas”.

- "En el merendero le dan leche a los chiquilines, pero no los puedo dejar ir solos, prefiero hacerles la leche aquí".

- "Donde nosotros vivíamos era uno de los peores lugares. Por ese motivo tuvimos que abandonar una casa terminada y un almacén funcionando".

- "Usted no puede dejar a su hijo en una esquina con otros muchachos, porque por ahí están tomando cocaína o cemento”.

- Una mujer afirma que luego de un robo en la casa: "Las salidas a partir de ahí las cortamos, y ya van a ser dos años. Sólo que tengamos alguien que se quede acá. Si no, no salimos".

- "Son unos ladrones. No podés salir dos horas que te roban todo".

Fuente: Suárez (2004) y Zaffaroni (1999).

utilizan los empleadores cuando reclutan mano de obra no calificada. A su vez, el reconocimiento de que los residentes de esas áreas son rechazados como potenciales candidatos a puestos de trabajo por el lugar donde viven lleva a muchos de los jóvenes que buscan trabajo a ocultar sus domicilios reales.

\section{b) Mecanismos de socialización}

Estos mecanismos —que incluyen fenómenos tales como la existencia en el entorno vecinal de modelos de rol, la eficiencia de los patrones normativos comunitarios y la presencia de subculturas marginales- están estrechamente interrelacionados. En lo que concierne a los vínculos con el mercado laboral, la consecuencia más importante de su funcionamiento es el grado de exposición de las personas a señales, imágenes y hábitos que justifican y refuerzan el desaliento, cuestionan la posibilidad de superación de la pobreza a través del trabajo, o restan valor a contenidos mentales congruentes con la formación de una cultura del trabajo.
Un primer factor en este sentido es la ausencia en el entorno social inmediato de modelos de rol que traduzcan las expectativas, hábitos y tipos de comportamiento vinculados al trabajo que predominan en los circuitos sociales y económicos principales de la ciudad. Tales modelos constituyen ejemplos vivientes de la posibilidad de salir de la pobreza y elevar el bienestar familiar utilizando las oportunidades que se hallan dentro del marco legal que regula al mundo laboral. ${ }^{16} \mathrm{El}$ contacto regular con esas personas puede contribuir a elevar las expectativas de bienestar futuro, a estimular la ética y la disciplina de trabajo y, en particular, a fortalecer el convencimiento de que las inversiones continuadas en educación y capacitación serán eventualmente premiadas con logros significativos. La

\footnotetext{
${ }^{16}$ La función de "modelo de rol" también puede ser cumplida por vecinos que alcanzan éxitos económicos por vías ilegales, fenómeno frecuente en barrios con actividades delictivas organizadas, como el tráfico de drogas y los "desarmaderos" de autos robados, o cuasidelictivas como el contrabando "hormiga" de mercaderías.
} 
abundancia de casos de movilidad descendente en los barrios pobres de Montevideo ciertamente no genera condiciones favorables a ese tipo de contactos.

Otros dos factores, estrechamente interrelacionados, plantean condiciones desfavorables para la formación de una cultura del trabajo. Uno es la ineficiencia de los patrones normativos que regulan la convivencia entre los vecinos, dimensión central del capital social comunitario. Las urgencias que plantean a los hogares las necesidades cotidianas de supervivencia, así como la carencia e inestabilidad de los recursos mínimos necesarios para alimentar redes de reciprocidad o instituciones de base comunitaria, conspiran contra la generación y mantenimiento de patrones generales de convivencia. El otro, que suele emerger como su contrapartida, es la presencia de subculturas marginales. Los barrios con altas concentraciones de pobreza experimentan, de manera constante y larvada, una pugna entre una y otra opción, entre quienes procuran resistir la desafiliación social y quienes, víctimas ya del desaliento, aceptan la ruptura con los marcos normativos generales y exploran vías no legítimas para mejorar sus condiciones de vida. Al prestar apoyo a los que transitan esas vías, las subculturas marginales restan atractivo al trabajo como medio para alcanzar metas de bienestar.

\section{V}

\section{Consideraciones finales}

Este artículo ha querido presentar un conjunto de reflexiones y de antecedentes empíricos sobre dos procesos que están afectando las características de la pobreza en la ciudad de Montevideo: el debilitamiento de los vínculos de los trabajadores menos calificados con el mercado de trabajo urbano y la creciente concentración de esos trabajadores y sus familias en barrios con alta densidad de pobreza. Si bien están lejos de ser concluyentes, los resultados de este ejercicio sugieren la conveniencia de investigar más a fondo la relación entre los cambios en la morfología social de la ciudad, por un lado, y la segmentación de su mercado de trabajo, por otro, teniendo en cuenta la posibilidad de que haya hallazgos espurios, examinando de manera pormenorizada el peso relativo de una u otra dirección causal (del contexto al individuo y del individuo al contexto) y buscando revelar las complejas facetas de los mecanismos que intervienen entre los contextos y sus eventuales efectos sobre las personas. Como se observa, lo anterior configura todo un programa de investigación.

¿Qué es lo que justifica llevar a cabo tal programa? El argumento principal para hacerlo es que, de corroborarse las tendencias a una distribución espacial cada vez más polarizada de las clases en las ciudades, y de verificarse que en los barrios más desaventajados se activan mecanismos que realimentan el aislamiento social de sus residentes, estaríamos en presencia de procesos que, si no son contrarrestados con eficacia, conducirán ineludiblemente a una reproducción am- pliada de las desigualdades, ya extremadamente marcadas, de las que adolecen las grandes ciudades de la región. Toda estrategia de intervención dirigida a promover la integración sobre la base de la equidad, la construcción de ciudadanía y el fortalecimiento del tejido social deberá desactivar esos procesos y, por ende, necesitará contar con diagnósticos que ayuden a entender mejor la naturaleza de esta relación perversa entre territorio y trabajo. ${ }^{17}$

Cabe añadir que la observación de los cambios en la estructura productiva de la ciudad sugiere que las posibles reactivaciones futuras de la capacidad de absorber empleo tendrán un marcado sesgo a favor de los más calificados, y que las diferencias de ingreso y de condiciones de trabajo seguirán acentuándose en torno a ese eje. Los efectos de los mecanismos socializadores e instrumentales en los barrios donde se concentran cada vez más los hogares con grandes carencias vendrían a reforzar las tendencias señaladas.

Para simplificar la exposición, en este análisis se ha dado un carácter quizás demasiado lineal y determinístico a los factores que impulsan la exclusión social

\footnotetext{
17 Habría que emprender exploraciones similares de los mecanismos que afectan el acceso a servicios que son fuente de activos en capital físico, humano y social, como la educación, la salud, la infraestructura de vivienda, la seguridad pública, la actividad política, los lugares de esparcimiento y cuya activación suele estar estrechamente vinculada con los procesos de segregación espacial de los pobres urbanos.
} 
de los trabajadores urbanos menos calificados. En rigor, las fortalezas relativas de los factores de exclusión y de inclusión están sujetas a un escenario de posibilidades. Pero las pugnas entre esos factores están presentes, en formas manifiestas o larvadas, en cada barrio. Hay quienes resisten la desafiliación social y quienes se abandonan a ella, conformándose con una "ciudadanía de segunda". Lo que se afirma en este ensayo es que, en el Montevideo de los últimos años, el balance de tal pugna se ha inclinado hacia esta última opción.

En el área laboral, da sostén a esa visión pesimista la conclusión de que los residentes de barrios pobres segregados sólo podrán aprovechar las oportunidades de una eventual reactivación si el tiraje de la chimenea económica es mucho más fuerte que en el pasado. De hecho, no hay por qué suponer que demandas de empleo suficientemente intensas no puedan neutralizar los mecanismos analizados, devolviendo esperanzas a los que las perdieron y generando, entre los que nunca las tuvieron firmes, esperanzas de alcanzar condiciones de vida dignas con su propio esfuerzo. Si ese fuera el caso, parecería razonable anticipar que, en cada barrio segregado, las señales positivas de empleo irán reforzando la posición de los que resisten la desafiliación y restando argumentos a los desalentados y rebeldes.

El problema reside más bien en cuán realista es un escenario de ese tipo en el corto y mediano plazo. $\mathrm{Si}$ para hacer esa apreciación se parte de las actuales tendencias en la situación de empleo en las grandes ciudades latinoamericanas, cabe observar que ellas — salvo en México, que comparte fronteras con el mercado de trabajo más dinámico del mundo- mantienen tasas de desempleo relativamente altas que afectan en particular a los trabajadores de menor calificación. Al igual que en Montevideo, esto tiene que ver con los ritmos de crecimiento débiles e inestables de las economías y con el hecho de que el dinamismo de dicho crecimiento está fuertemente atado a actividades pro- ductivas de creciente densidad tecnológica. En tales circunstancias, es difícil identificar elementos sobre los cuales edificar expectativas de mejoras importantes en las tasas de desempleo, en los índices de precariedad e inestabilidad del trabajo y en las diferencias de remuneraciones entre trabajadores calificados y no calificados, por lo menos a corto y mediano plazo. De ser así, no cabría esperar que se desactiven mecanismos como los aquí expuestos.

Si la mirada se vuelca a la inserción laboral de las próximas generaciones, el problema fundamental es cómo elevar el nivel de calificación de los niños de hogares pobres y achicar las brechas educativas entre las clases urbanas. Existen numerosos estudios que entregan señales acerca de los efectos que tienen sobre el desempeño escolar de los niños mecanismos similares a los aquí planteados que se activan en barrios con fuertes carencias. El tipo de inversiones educativas necesarias para neutralizar esos efectos y generar esperanzas de futuro en esos niños y adolescentes es el que exige un fuerte aumento del tiraje de la chimenea educativa, potenciando su capacidad de absorber y retener a aquellos menores, cuyos entornos de socialización primarios muestran fuertes deficiencias, y de elevar la calidad de la enseñanza que se les brinda.

En cuanto al ordenamiento del territorio urbano, cabe plantear medidas para revertir o frenar los procesos de segregación residencial, pero se debe tener en cuenta que los costos económicos y políticos de ellas se elevan en forma exponencial a medida que van cristalizando las subculturas marginales La consolidación de esas subculturas suele ser paralela al debilitamiento del mundo del trabajo como eje de la formación de las identidades adultas urbanas, así como de las expectativas de ascenso social y de integración efectiva en los circuitos económicos y sociales principales de la sociedad. Al igual que en otras áreas de las políticas sociales, la mejor intervención en este campo es la preventiva.
Álvarez, M.J. (2002): Asentamientos irregulares en Montevideo: la desafiliación resistida, documento de trabajo, Montevideo, Facultad de Ciencias Sociales, Universidad de la República. (2004): Moving to a Golden Ghetto, tesis, Pittsburgh, Departamento de Sociología, Universidad de Pittsburgh.

Amarante, V., R. Arim y A. Vigorito (2004): Pobreza, red de protección social y situación de la infancia en Uruguay, Washington, D.C., Banco Interamericano de Desarrollo (BID), borrador.
Becker, J., J. Jager y W. Raza (2001): Economía política de Montevideo: desarrollo urbano y políticas locales, Montevideo, Centro Latinoamericano de Ecología Social (CLAES).

Caldeira, T. (2000): City of Walls: Crime, Segregation and Citizenship in São Paulo, California, University of California Press.

Cecilio, M. (1996): Relevamiento de asentamientos irregulares en Montevideo, Asentamientos irregulares, Montevideo, Ministerio de Vivienda, Ordenamiento Territorial y Medio Ambiente. 
CEPAL (Comisión Económica para América Latina y el Caribe) (1997): Panorama social de América Latina, 1996, LC/G.1946-P, Santiago de Chile. Publicación de las Naciones Unidas, $\mathrm{N}^{\circ}$ de venta: S.97.II.G.4.

Cervini, M. y M. Gallo (2001): Un análisis de exclusión social: la segregación residencial entre los barrios de Montevideo, 19861998, tesis de grado del FCE, Montevideo.

Granovetter, M. (1985): Economic action, social structure and embeddedness, American Journal of Sociology, vol. 91, $\mathrm{N}^{\circ} 3$, Chicago, The University of Chicago Press.

INE (Instituto Nacional de Estadística) (1998): VII Censo General de Población, III de Hogares y V de Viviendas, Montevideo. (2002): Evolución de la pobreza por el método del ingreso, 1986-2001. Montevideo.

(2003): Estimaciones de pobreza por el método del ingreso. Año 2002, Montevideo.

(2004): Estimaciones de pobreza por el método del ingreso. Año 2003, Montevideo.

Jencks, Ch. y S. Mayer (1990): The social consequences of growing up in a poor neighborhood, en L. Lynn y M. McGeary (comps.), Inner City Poverty in the United States, Washington, D.C., National Academy Press.

Kaztman, R. (coord.) (1999): Activos y estructura de oportunidades: estudio sobre las raíces de la vulnerabilidad social en Uruguay, LC/MVD/R.180, Montevideo, Oficina de la CEPAL en Montevideo.

Kaztman, R. (2002): Convergencia y divergencia: exploración sobre los efectos de las nuevas modalidades de crecimiento sobre la estructura social de cuatro áreas metropolitanas, en R. Kaztman y G. Wormald (coords.), Trabajo y ciudadanía: los cambiantes rostros de la integración y la exclusión social en cuatro áreas metropolitanas de América Latina, Montevideo, Cebra.

Kaztman, R., G. Corbo y otros (2003): La ciudad fragmentada: respuesta de los sectores populares urbanos a las transformaciones del mercado y del territorio en Montevideo, Working Papers Series, $\mathrm{N}^{\circ}$ 02, Austin, University of Texas.

Lombardi, M. (1989): La cuestión urbana uruguaya: una nueva realidad de partida, en M. Lombardi y D. Veiga (comps.), Las ciudades en conflicto: una perspectiva latinoamericana, Montevideo, Centro de Informaciones y Estudios del Uruguay (CIESU).

Luna, J.P. (2004): La política desde el llano: conversaciones con militantes barriales, Montevideo, Ediciones de la Banda Oriental.

Massey, D. y A. Gross (1994): Migration, segregation, and the geographic concentration of poverty, American Sociological Review, vol. 59, $\mathrm{N}^{\circ} 3$, Washington, D.C., American Sociological Association.

Mazzei, E. y D. Veiga (1985a): Pobreza urbana en Montevideo: nueva encuesta en "Cantegriles", Cuadernos de Ciesu, No 47, Montevideo, Ediciones de la Banda Oriental.

(1985b): Pobreza urbana en Montevideo, Montevideo, Centro de Informaciones y Estudios del Uruguay (CIESU).

(1986): Una experiencia de investigación en un área de pobreza crítica de Montevideo, Revista de ciencias sociales, $\mathrm{N}^{\mathrm{o}}$ 1, Montevideo.
MEMFOD (Programa de Modernización de la Educación Media y Formación Docente) (2002): Jóvenes, educación y trabajo. Un análisis del proceso de inserción laboral en los jóvenes que han abandonado sus estudios, Cuaderno de trabajo $\mathrm{N}^{\circ} 1$, Montevideo, Comisión de Transformación de la Educación Media Superior en Uruguay (TEMS).

Park, R.E. (1926): The urban community as a spatial pattern and a moral order, en E.W. Burguess y R.E. Park (comps.), The Urban Community, Chicago, University of Chicago Press.

Pellegrino, A., D. Macadar y otros (2002): Proyecto segregación residencial en Montevideo: ¿un fenómeno creciente?. Montevideo, Proyecto de la Comisión Sectorial de Investigación Científica (CSIC), Universidad de la República, Concurso de Proyectos I+D del año 2000.

PNUD (Programa de las Naciones Unidas para el Desarrollo) (2001): Informe de desarrollo humano en Uruguay, 2001, Montevideo.

Portes, A. (1989): La urbanización de América Latina en los años de crisis, en M. Lombardi y D. Veiga (comps.), Las ciudades en conflicto: una perspectiva latinoamericana, Montevideo, Centro de Informaciones y Estudios del Uruguay (CIESU).

Rama, G. (1971): El club político, Montevideo, Editorial Arca.

Retamoso, A. (1999): El dinamismo poblacional del área metropolitana, Estudios sociales sobre educación, № 8. Montevideo, Administración Nacional de Educación Pública (ANEP).

Rodríguez, J. y C. Arriagada (2004): Segregación residencial en la ciudad latinoamericana, Eure, vol. 29, N 89, Santiago de Chile, Pontificia Universidad Católica de Chile.

Sampson, R.J., J. Morenoff y T. Gannon-Rowley (2002): Assessing "neighborhood effects": social processes and new direction in research, Annual Review of Sociology, vol. 28, Palo Alto, California, Annual Reviews.

Saravi, G. (2004): Segregación urbana y espacio público: los jóvenes en enclaves de pobreza estructural, Revista de la CEPAL, $\mathrm{N}^{\circ}$ 83, LC/G.2231-P, Santiago de Chile, agosto.

Small, M. y K. Newman (2001): Urban poverty after the truly disadvantaged: the rediscovery of the family, the neighborhood, and culture, Annual Review of Sociology, vol. 27, Palo Alto, California, Annual Reviews.

Suárez, A.L. (2004): Inserción laboral de residentes en asentamientos urbanos del Gran Buenos Aires, documento presentado a las Jornadas 2004 de la Universidad Nacional de General Sarmiento, inédito.

Svampa, M. (2002): Las nuevas urbanizaciones privadas. Sociabilidad y socialización: la integración social "hacia arriba", en S. Fieldman (comp.), Sociedad y sociabilidad en la Argentina de los 90, Buenos Aires, Biblos.

Wilson, W. (1997): When Work Disappears: The World of the New Urban Poor, Nueva York, Vintage Books.

Zaffaroni, C. (1999): Los recursos de las familias urbanas de bajos ingresos para enfrentar situaciones críticas, en R. Kaztman (coord.), Activos y estructura de oportunidades: estudio sobre las raíces de la vulnerabilidad social en Uruguay, LC/ MVD/R.180, Montevideo, Oficina de la CEPAL en Montevideo. 